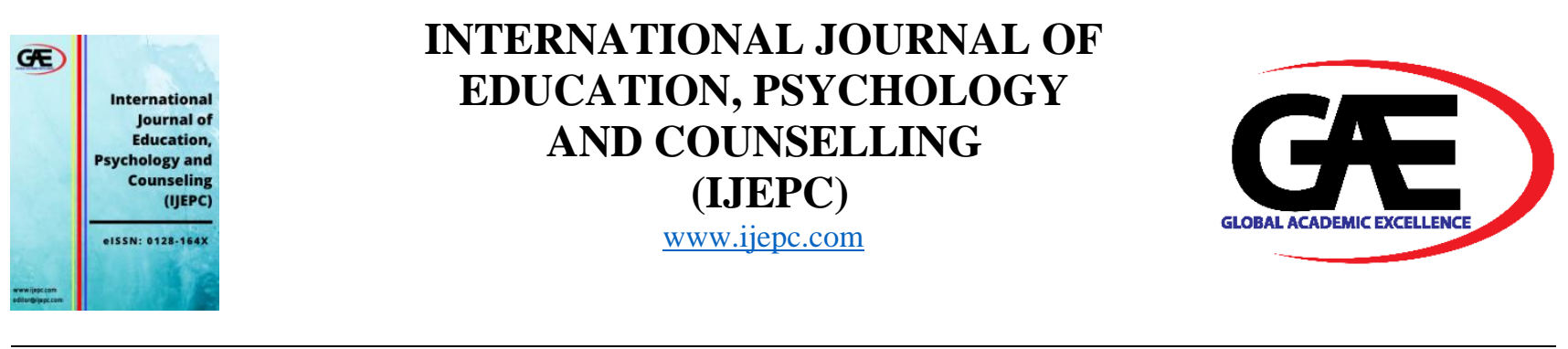

\title{
METACOGNITIVE READING STRATEGIES APPLICATION AMONG HIGH AND LOW PROFICIENT READERS AT PRE- UNIVERSITY LEVEL
}

\author{
Naimah Derin 1*, Suyansah Swanto ${ }^{2 *}$, Abd Halib Mohd Ali ${ }^{3}$, Wardatul Akmam Din ${ }^{4}$ \\ 1 Faculty of Psychology \& Education, Universiti Malaysia Sabah, Malaysia \\ Email: naimahderin@gmail.com \\ 2 Faculty of Psychology \& Education, Universiti Malaysia Sabah, Malaysia \\ Email: suyansah@ums.edu.my \\ 3 Faculty of Psychology \& Education, Universiti Malaysia Sabah, Malaysia \\ Email: abdhalib@gmail.com \\ 4 Faculty of Psychology \& Education, Universiti Malaysia Sabah, Malaysia \\ Email: wardadin@ums.edu.my \\ Corresponding Author
}

\section{Article Info:}

Article history:

Received date: 11.09 .2021

Revised date: 10.10 .2021

Accepted date: 15.11 .2021

Published date: 30.11 .2021

To cite this document:

Derin, N., Swanto, S., Ali, A. H. M., Din, W. A. (2021). Metacognitive Reading Strategies Application Among High And Low Proficient Readers At Pre-University Level. International Journal of Education, Psychology and Counseling, 6 (43), 249-263.

\section{DOI: $10.35631 /$ IJEPC.643020}

This work is licensed under $\underline{\mathrm{CC} B Y} 4.0$

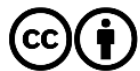

Abstract:

In higher education, reading of academic texts is considered as an essential access to scientific knowledge. Therefore, in this survey study will utilize the inventory of Survey on Reading Strategies Questionnaire (SOR) developed by Mokhtari and Sheory. It is explored to identify the two types of readers: high (HPR) and low (LPR) proficient readers at Form Sixth Cenre of Government School in Sabah, Malaysia. There are three major reading strategies: GLOB (Global), SUPP (Support) and PROB (Problem Solving) strategies. This quantitative approach is done by operating the descriptive (mean and standard of deviation) and inferential (Magnitude of effect) statistics. 250 participants from pre-university students randomly selected to respond to the questionnaire The questionnaire finding revealed that PROB strategy was favoured by both readers. To strengthen scrupulous answer, Effect size had given a better interpretation of the finding. The questionnaire provided all reading strategies to be negative effect to the high proficient readers (HPR) yet large positive effect to the low proficient readers (LPR).

Keywords:

Global Reading Strategy, Support Reading Strategy, Problem Solving Reading Strategy, High Proficient Reader And Low Proficient Reader. 


\section{Introduction}

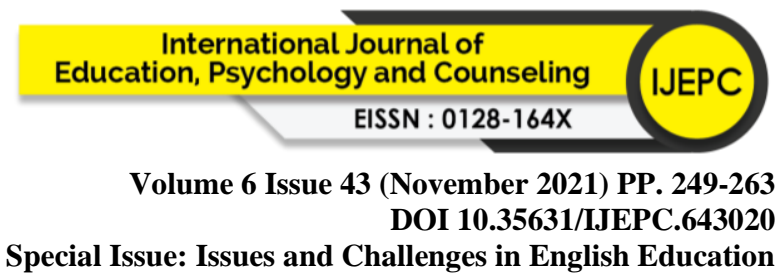

It was quite perplexing to understand how reading strategies related to the text as reading is known as very personal cognitive activity. Thus, the reading proficient today is drastically important particularly to the adult readers. The ability to read efficiently is particularly important in educational contexts, where second language (L2) is concerned.

This research investigates how a group of pre-university students cope with reading tasks. Specifically, it highlights the reading strategies that the students self-report while reading academic texts in English. Reading strategies are defined here as "deliberate, conscious procedures used by readers to enhance text comprehension" (Sheorey \& Mokhtari, 2001, p.433), and their application is believed to contribute to efficient reading (Auerbach \& Paxton, 1997, p. 240- 241).

There is a considerable body of literature on the awareness of the reading process and reading strategy used by readers with a variety of proficiency levels, first language (L1), cultural backgrounds, and school contexts. (Auerbach \& Paxton, 1997; Grabe,1991; Barnett, 1989). Since college and pre-university students need to cope with a large amount of academic reading tasks, the importance of finding out about their reading strategy awareness with a view to providing improved $\mathrm{L} 2$ reading instruction is worth to be investigated.

In recent years, an increasing number of researchers believe that the reading process is an active practice in which reading skills can be developed. The viewpoint has moved from the "text as object" to that of the "text as process" by encouraging close interaction between the reader and the text. In addition to model-making in second language reading during the two decades, considerable attention has been paid to understanding what competent, skilled readers typically do while reading, including identifying the strategies they use and how and under what conditions they use those strategies. This line of research has been useful and crucial in instructing low competent first (L1) and second language (L2) readers to increase their awareness and use of reading strategies to improve comprehension (Garner, 1985).

Therefore, this study aims to provide a picture of the strategies awareness of the reading process, or "perceptions about the reading strategies" (Barnett, 1989, p.75) of a group of L2 students when reading academic materials (textbooks, journal articles, etc.) in English. Two research questions are suggested as follows:

(1) What reading strategies reportedly used by the participants?

(2) What is effect size on reading strategies for low and high proficient readers?

\section{Literature Review}

This research had identified and discussed about the theoretical concept and models that were adapted to answer the research needs such as the concepts of reading strategies, relationship of cognitive theory with language acquisition, who are the low and high proficient readers and the studies done on metacognitive reading strategies. 


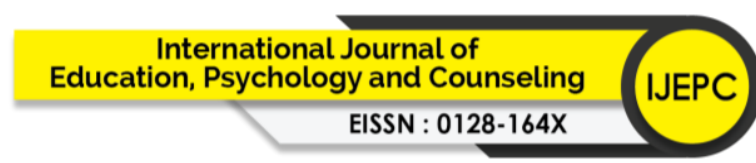

Volume 6 Issue 43 (November 2021) PP. 249-263

DOI 10.35631/IJEPC.643020

Special Issue: Issues and Challenges in English Education

Enhancing the study, Piaget (1955) has contributed to the discovery of the nature of knowledge (Flavell, Miller \& Miller, 2002) which he created the theory of cognitive development. Influenced by Piaget's cognitive development theory, Flavell starts to develop the concept of metacognition around 1971. Flavell entitled "Metacognitive Aspects of Problem Solving." In this article, Flavell (1976) defines metacognition as "one's knowledge concerning one's own cognitive processes and products, or anything related to them" (p.232). Flavell further explains that metacognition is "the active monitoring and consequent regulation and orchestration of these processes in relation to the cognitive objects or data on which they bear, usually in the service of some concrete goal or objective" (Flavell, 1976, p.232). Flavell's model is the foundation for research in the field of metacognition today. The works of both Piaget and Flavell serve as a basis for the study of metacognition across multiple groups. Metacognitive awareness is also critical to second language acquisition. Consequently, reading theories assume processes, representations, and outcomes of comprehension develop by same basis of cognitive processes.

Discourse psychologists have developed several theoretical models of text comprehension during the last two decades. These theories make different commitments on the role of comprehension strategies in driving comprehension. There are two prominent reading theories to strengthen this study: (1) Schema Theory, (2) Human Cognitive System.

Schema Theory- A more recent theory of reading comprehension is called "schema theory" or the "schema perspective." The goal of schema theory is to describe interaction between what is in the text and how that information is shaped and stored by the reader. The underlying assumption is that- meaning does not lie solely in the print itself but interacts with the cognitive structure or schemata already present in the reader's mind. These schemata represent, in Ausubel's (1968) terms, the "ideational scaffolding" or framework for understanding new information. Thus, the reader has present in cognitive structure schemata which constitute a cognitive filter through which one views the world and from which one predicts or makes inferences about what is read. Schemata, according to Rummelhart (1977) and Ortony (1975), represent generic concepts which are stored in memory. The way in which a particular concept is stored is not by remembering that isolated event in its totality down to its most basic components, but by identifying those aspects of the event related to other concepts already stored.

Generalized schemata allows us to learn or make sense of a wide array of information or very abstract ideas, and these generalized schemata can be modified or adapted as we learn new information. This idea is almost identical to the Piagetian concepts of assimilation and accommodation except that schema theory limits the input to printed material. In Piaget's definition assimilation takes place when new knowledge is integrated into a pre-existing knowledge base. Thus, accommodation occurs when the knowledge base or a schema is changed to fit in new information.

Human Cognitive System- There is another aspect involving cognitive and problem solving called Verbal report'. The verbal report process can be obtained through human cognitive system also known as Long Term Memory (LTM) and Working Memory (WM). LM is the past where knowledge is stored permanently. It takes sometimes to store into there and can be obtained later to be used again. At the other end we find the sensory system that transform 


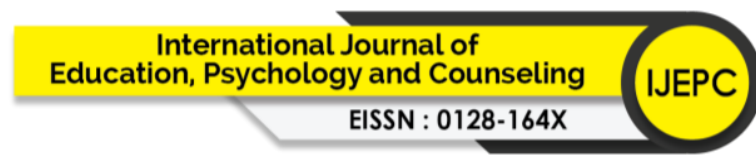

Volume 6 Issue 43 (November 2021) PP. 249-263

DOI 10.35631/IJEPC.643020

Special Issue: Issues and Challenges in English Education

information from the environment into an internal form. WM on the other hand is the part where the currently 'active' information resides. The model of cognitive system extracted from Theory of Human Memory by Newell and Simon (1972). There are five processes to represent human cognitive system:

(1) Perception: Information flows from the sensory buffer into working memory.

(2) Retrieval: Information is retrieved from long-term memory into working memory. It still exists in long-term memory but is activated into working memory.

(3) Construction: New information is constructed from other information in working memory. For example, when solving the physics problem, someone may note that 'slowly moved piston' may in general refer to 'adiabatic process' and the resulting new association between these concepts are stored as a new object in working memory.

(4) Storage: Stores information from working memory into long-term memory.

(5) Verbalization: Information that is active in working memory is put into words. The output of this process is the spoken protocol.

This model has several important implications for the meaning of verbal reports. One important point is that the information that can be verbalized is the content of working memory. This means that the content of long-term memory (the general knowledge) cannot be verbalized (unless it is somehow retrieved rather than used), nor can the cognitive architecture, the machinery, that applies the knowledge to be verbalized. About these aspects only indirect knowledge is available.

\section{Terms Definition}

\section{Reading Strategies}

The term 'strategy' can be operationalized as learning techniques or behaviours that help learners to iron out the frequent difficulties encountered whenever learning is taking place and enable them to interact with the written passages effectively and efficiently. This concept has been defined differently by numerous specialists. Anderson (1991) defined it as deliberate cognitive steps that readers can take to assist in acquiring, storing, and retrieving new information' (Anderson, 1991, p.460). Therefore, it can be obviously stated that reading strategies are paramount for they enable readers to better tackle different reading tasks, and construct meaning from the written passages as competently as possible. These strategies may involve a wide range of cognitive mental activities which can be summarized as follows: the strategies may involve skimming, scanning, guessing, recognizing cognates and word families, reading for meaning, predicting, activating general knowledge, making inferences, and separating main ideas from supporting ideas (Phan, 2006, p. 01).

Furthermore, there are other more recently recognized text-processing strategies such as activating prior knowledge, and recognizing textual organization, which have been added to the list of strategic behaviours. These strategies discussed above have been later grouped by Carrell (1989) as 'local' bottom-up decoding types of reading strategies and 'global', top-down types of reading strategies. As the former, it concerns sound-to-letter correspondence (phonetics-based approach); the latter has to do with readers' activated background knowledge (readers-driven types of information processing) and recognizing text structure. Reading researchers generally typify reading strategies into two main categories: cognitive and 


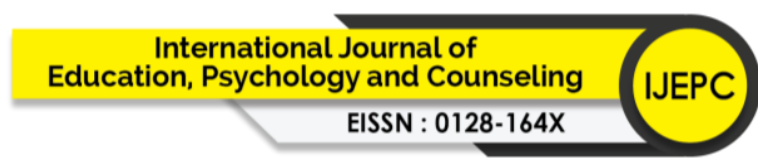

Volume 6 Issue 43 (November 2021) PP. 249-263

DOI 10.35631/IJEPC.643020

Special Issue: Issues and Challenges in English Education metacognitive reading strategies. Cognitive strategies serve as primordial learning techniques that assist learners in constructing meaning from the text, which are made up of bottom-up and top-down strategies. In the case of using bottom-up reading strategies, the learners' minds, repeatedly engage in a variety of processes. Readers start by processing information at the sentence level. In other words, they focus on the identification of the meaning and grammatical category of a word, sentence, syntax, text detail and so forth (Salataci \& Akyel, 2002, p.02).

Whereas top-down strategies consist of integrating one's background knowledge to the reading process to construct meaning from a text rather than passively identifying words in the text, predicting, and getting the gist of text or skimming. In this sense, 'reading is asking questions of printed text, and reading with comprehension becomes a matter of getting your questions answered' (Smith, 1975).

Ultimately, Pressley (1998), emphasised on metacognitive reading strategies where metacognition is knowledge about thinking, and metacognition about reading is specifically knowledge about reading and how reading is accomplished. He added, skilled readers know how to get meaning from text. At the letter and word levels, they know how to decode words and are very acquainted of the need to attend carefully to the individual letters and letter combinations in words that are not immediately recognizable, that sounding out words and blending the sounds is how to recognize unfamiliar words.

However, in previous study focusing on to tertiary level, the lack of reading habits is still prevalent. In a study conducted by Abdul Kadir (2005) at Universiti Teknologi MARA Office Management students, found that some students failed to complete their studies. One of the reasons is due to having poor reading interest. He commented that his students do not make reading their habit and they hardly read any reading material during their free time. Thus, undergraduates are facing problems in their reading. This could be due to incomprehensibility of text, inability to interact with text and low motivation for reading (Palincsar \& Brown, 1985). Palincsar \& Brown (1984) commented that students are adequate decoders but poor in comprehension and this pose a major hurdle for the undergraduates when they need to read a lot of academic texts in order to do their assignments and it cannot be denied that Diploma students and undergraduates need to read a lot of academic texts, journals, websites and magazines regularly which require them to use high level of reading skills and therefore making reading an effortful activity. Due to this reason, many students often choose not to read. They read too little and rarely read for deep understanding (Guthrie, Schafer, \& Huang, 2001). Furthermore, based on the same research, the result showed that, female students scored higher than the male students. Both groups were using more of the cognitive reading strategies than the metacognitive strategies.

In more recent case study in a public senior high school in Indonesia, conducted by Manalu \& Wirza (2021), collected from 68 EFL students by assigning reading comprehension tests and administering MARSI (Metacognitive Awareness Reading Strategy Inventory), shows that the low achieving students are aware of their metacognitive reading strategies while reading and using them frequently to monitor their reading comprehension towards visual text modes.

Frequently, the problem-solving strategy gained the highest average score for a high level of knowledge. It reveals that low achieving students have achieved an overpowering choice for problem-solving strategy, which is more important than the two remaining strategies, the global 


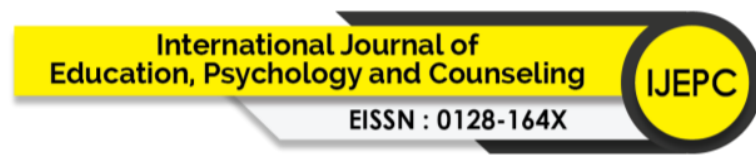

Volume 6 Issue 43 (November 2021) PP. 249-263

DOI 10.35631/IJEPC.643020

Special Issue: Issues and Challenges in English Education reading strategy, and support reading strategies. The finding also reported that, how students re-read the text for better understanding, they go back to every sentence or paragraph, pause and stop while reading intentionally to read slowly and carefully and to adjust reading rate, visualize information while reading, and these activities define as problem solving strategies, they employed to understand certain kind of text mode especially in visual text mode.

\section{Reading And Comprehension}

Assumptions on reading comprehension processes for the mature reader; reading usually appears to be an instantaneous and unified process. Under the scrutiny of research, however, this impression is inaccurate. Reading is not a single mental operation; rather, theorists distinguish among component processes of reading at the word, sentence, and text level. These component processes are implicated in generating of meaning representations of the text at different levels of abstractness (e.g., Balota, Flores d'Arcais, \& Rayner, 1990; Haberlandt \& Graesser, 1985; Van Dijk \& Kintsch, 1983; Just \& Carpenter, 1980). Each of the component processes of reading is thought to consist of sub processes. Word-level processes, for example, include encoding and lexical access. Encoding operations transform the visual characters of a word into a mental representation that forms the basis for word recognition. Lexical access refers to the process of recovering the word's meaning from memory. Researchers isolate sub processes like encoding and lexical access by documenting that each is sensitive to manipulations of specific stimulus factors and independent of others. Manipulations in word length, for example, are assumed to affect encoding but not lexical access, whereas familiarity affects lexical access but not encoding (Bower \& Clapper, 1989; Just \& Carpenter, 1987). Sentence-level processes include syntactic parsing processes. Using surface markers, word class, word position, and punctuation, these processes organize the words of sentences into a syntactic structure. Drawing on information from across the text, text-level processes establish links between a sentence and the previous text. This is achieved via a range of inferences including anaphoric, backward, and elaborative inferences. Inferences take advantage of causal connections in the text and of a reader's general knowledge of the world.

Comprehension depends on activation of information; as the reader processes the sentences of a passage; new information is integrated with the existing representation. Information is linked with antecedents; linkage requires that the antecedents be active in working memory or be reinstated if they are inactive (e.g., Gernsbacher, 1990; Just \& Carpenter, 1987; Dell, McKoon, \& Ratcliff, 1983; Van Dijk and Kintsch, 1983; Fletcher, 1981). Activation theories imply an inhibitory or dampening mechanism that prevents swamping the text representation and the rest of memory with activation; once a referent is activated and the new information is integrated, new concepts are activated. Whether they displace previous concepts or actively suppress them remains unresolved (e.g., Gernsbacher, 1990). The activation concept is ubiquitous in reading research; its measurement, however, is controversial and far from simple, regardless of the measurement technique used.

\section{Proficient and Low Proficient Readers' Characteristics}

In the current literature exploring reader behaviour either directly or indirectly, a variety of terms have been used to delineate different types of readers. These dichotomous modifiers include good versus poor, proficient versus less-proficient, successful versus unsuccessful, fluent versus non-fluent, skilled versus unskilled, and fast versus slow. While in most cases these terms are used interchangeably by various authors. This research adopts more motivated 


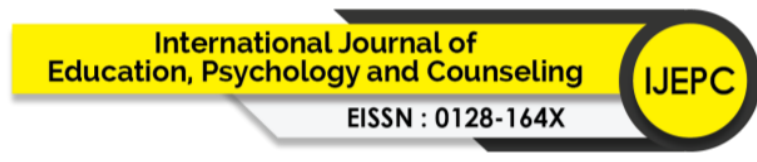

Volume 6 Issue 43 (November 2021) PP. 249-263

DOI 10.35631/IJEPC.643020

Special Issue: Issues and Challenges in English Education term that is 'proficient and low proficient readers, for whatever it be termed to, it still brings the same connotation to suit the research topic.

Therefore, in a study of higher-level and lower-level text processing skills in advanced reading comprehension in English as a second language (ESL), Nassaji (2003) found lower-level processes like word recognition, in addition to higher-level syntactic and semantic processes, contributed significantly to the distinction between skilled and less-skilled ESL readers. He concluded that efficient lower-level word recognition processes are integral components of L2 reading comprehension, and these processes must not be neglected even in highly advanced ESL readers. Poor L2 readers are slower in word recognition and generally weak at rapid and automatic syntactic processing because they "develop an overt knowledge of L2 grammatical structures before they become fluent L2 readers" (Grabe \& Stoller, 2002, p. 23). Chen (1998), in his proficiency constrained model of Chinese readers of English as a foreign language (EFL) in comprehending ambiguous English sentences, demonstrated that poor L2 readers are particularly weak in processing more complex ambiguous sentences. He held that this weakness resulted from their lack of syntactic knowledge in the target language, which constrained their reading comprehension. Parry (1991) conducted a detailed longitudinal study of four college students learning vocabulary in an academic setting over 2 years. One of her findings was that guessing word meaning from context is not a successful strategy in students' vocabulary development. Although her study was not initially aimed at discovering characteristics of good readers, Parry's study did reveal that in respect to vocabulary growth, successful readers guess less but simply read much more, thus exposing themselves to many more words in meaningful contexts. As for vocabulary size for fluent L2 reading in the Dutch context, Hazenburg \& Hulstijn (1996) maintained that an L2 Dutch reader needs a minimum of 10,000 headwords to read university- level texts successfully.

On the other hand, good readers performed much better than poor readers in processing more complex ambiguous sentences. L2 reader's linguistic proficiency is therefore a key factor that constrains the reader's text comprehension. The Chinese college EFL readers can be considered to belong to an L2 intermediate proficiency group with a vocabulary size of about 3,000-4,000 words. Liu \& Bever (2002) also involved Chinese EFL college students as participants in their experiment to investigate the role of syntactic analysis in reading comprehension. One of their findings was that good readers did not exhibit apparent effort to use syntactic analysis in their comprehension processes. They accounted for this result by claiming that good readers were able to process sentences in a quick and subconscious manner because of their high L2 proficiency. In contrast, poor L2 competence can severely constrain the development of readers' abilities in cognitive and metacognitive strategy use, thus affecting their reading comprehension.

Contents wise, Carrell (1987), stated that when the content is kept constant, but the rhetorical structure is varied, good L2 readers recognize the discourse structures much better than poor readers, which helps good readers significantly in their understanding of text. In another study by Carrell (1992), 45 high-intermediate ESL students in an American university participated. They were presented with two texts of different discourse organizations; after reading, they were required to provide a written recall and to explain the discourse pattern of the texts. She observed that the good readers were those who were more aware of the discourse organization of the original texts to recall information and who could also better describe the patterns of the 


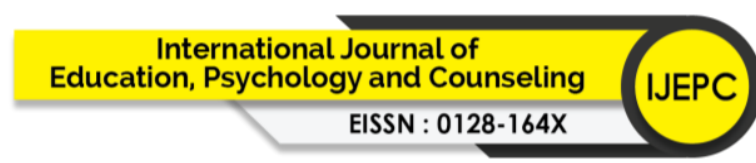

Volume 6 Issue 43 (November 2021) PP. 249-263

DOI 10.35631/IJEPC.643020

Special Issue: Issues and Challenges in English Education texts. This study further validated the facilitative role that discourse organization plays in L2 learners' reading comprehension. Good readers are more sensitive to the structural elements of the text, which helps them to remember the main idea of the text and comprehend better (Commander \& Stanwyck, 1997).

\section{Methods}

A quantitative design was exploited in this study, and it is more accurate by utilizing the magnitude of effect and the result would measure interval scale. The interval scale measurement described the variables in terms of some equal intervals between them. The scale allowed the participants to select an appropriate response in which the value fell in each interval (Awang, 2012). A number of 250 pre-university students from the form six centre at Sabah, aged about 19 to 20 years old had participated in this study.

There are 30 items questionnaire adapted from Mokhtari and Shoerey (2002) was administered in English. They are divided into three categories of reading strategies comprising of Global Reading Strategies (14 items), Support Strategies (7 items) and Problem-Solving Strategies (9 items). All the items in this questionnaire are mainly used to indicate the extent of awareness to which the participants perceived themselves for which strategies were utilized when reading academic materials. A 5 Likert scale indicates 1 (never" or almost never), 2 (occasionally, 3 (sometimes), 4 (usually) and 5 (always or almost always). Content validity was conducted prior to collection of data to ensure that the questionnaire represents the factors of measurement aimed for in this study.

In terms of data analysis, this study focused on descriptive statistics and inferential statistic (Effect size). Based on the research questions, the descriptive statistic was sufficient to describe the characteristics of the participants in a population. All data collected were processed using SPSS v22 and Excel program.

For further understanding, the excel program was utilized to perform the result which is one of the tools to assist the researcher to look for the effect size for each strategy correlate with each participants' category. It is believed that the quest for this report would be much effective by looking at the effect size and its prominence to this study as the hypothesis statistical significance procedures alone is insufficient. Carver (1978) stated that a statistical significance testing may breaches and corrupts the scientific method. In addition, Lane (1999) reported that null hypothesis statistical testing might make sense mathematically, but the results might be erroneous. Accordingly, Cohen (1988) suggested that the effect of less than 0.2 indicates no effect and effect size of 0.8 or more is large. When the effect size is at least 0.2 and less than 0.5 , the effect is small. Whereas, if the value is at least 0.8 , there is an effect of the strategies used. Likewise, if the value of at least 0.2 to 0.5 , it means that there will be moderate effect of each strategy.

\section{Results}

The result of data distribution for normality test showed the skewness and kurtosis statistics revealed the positive data distribution. Chua (2013) stated that, a 100\% normal distribution should have a value of zero (0) for its skewness and kurtosis. On the other hand, kurtosis shows the height of the distribution (high or low). A positive kurtosis value shows a high distribution curve known as leptokurtic and a negative kurtosis value shows a low distribution curve which 


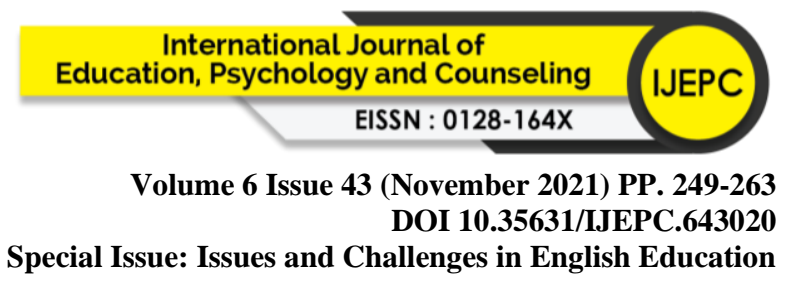

also known as platykurtic. Chua (2013) added that a data is normally distributed where the skewness and kurtosis values should be in the range of $\mathbf{- 1 . 9 6}$ to $+\mathbf{1 . 9 6}$. For this study, the results showed that both skewness and kurtosis values are .385 (Skewness) and 1.27 (Kurtosis) which this displayed the range values within normal distribution range. The alpha Cronbach had shown .792 which equal to $79 \%$ of the questionnaire items were reliable for the research.

\section{Questionnaire Results}

Table 1:Descriptive Statistic (Global Strategy)

\begin{tabular}{cll}
\hline NO & & Mean \\
\hline 3 & $\begin{array}{l}\text { I think about what I know to help understand what I read } \\
\text { I take an overall view of the text to see what it is about }\end{array}$ & 3.78 \\
4 & $\begin{array}{l}\text { before reading it. } \\
\text { I use context clues to help me better understand what I am } \\
17\end{array}$ & 3.56 \\
23 & $\begin{array}{l}\text { I cheading. } \\
\text { information. }\end{array}$ & 3.80 \\
24 & $\begin{array}{l}\text { I try to guess what the content of the text is about when I } \\
\text { read. }\end{array}$ & 3.82 \\
27 & $\begin{array}{l}\text { I checked to see if my guesses about the text are right or } \\
\text { wrong. }\end{array}$ & 3.68 \\
30 & $\begin{array}{l}\text { When reading, I think about information in both English } \\
\text { and my mother tongue. }\end{array}$ & 3.70 \\
\hline & & $\mathbf{3 . 7 0}$ \\
\hline
\end{tabular}

Table 1 shows the result on, Global strategy overall mean $=\mathbf{3 . 7 0}$. Only 7 out 14 items support the Global strategy with the mean above 3.50 which shows that most of the participants usually think about what they know to help them to understand what they read. They reported they do take overall view of the text before reading it other than utilizing the context clues to have better understanding of the text. When they came across new information, they usually checked their understanding and even guessed the contents of the text and checked whether their guesses were true or wrong. Lastly, the participants also think of the information in their mother tongue.

Table 2: Descriptive Statistics (Support Strategy)

\begin{tabular}{clc}
\hline NO & & Mean \\
\hline 10 & $\begin{array}{l}\text { I underline or circle information in the text to help me } \\
\text { remember it. }\end{array}$ & 3.98 \\
13 & $\begin{array}{l}\text { I use reference materials (e.g., a dictionary) to help me } \\
\text { understand what I read. }\end{array}$ \\
18 & $\begin{array}{l}\text { I paraphrase (restate ideas in my own words) to better } \\
\text { understand what I read. }\end{array}$ & 3.77
\end{tabular}




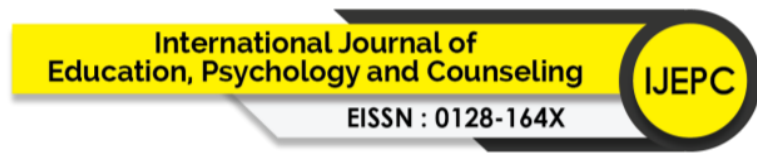

Volume 6 Issue 43 (November 2021) PP. 249-263

DOI 10.35631/IJEPC.643020

Special Issue: Issues and Challenges in English Education

I go back and forth in the text to find relationships among ideas in it.

26 I ask myself questions I like to have answered in the text $\quad 3.57$ language.

Table 2 shows Support strategies, mean shows a similar result as Global strategy (3.70). With 6 out of 7 items agree that the participants usually underline or circle the information in the text to help them to remember the information. Normally, they would use reference material like dictionary to assist them to understand texts. They even paraphrased in their own words for better understanding of texts. Other strategies reported were provided for better understanding, they always go back and forth in the text to find relationship among the information and asked questions to themselves about what they like the text to answer their questions. They admitted that they translated what they read from English to their native language. Responding to the last part, translation always time consuming if they need to answer question during examination where the strategy might not be effective. This supported by L2 readers which differ widely from L1 readers in terms of linguistic resources to supporting comprehension. Nuttall (2005) argued vocabulary was seriously challenged in L2 reading and further research clearly points at the link between a limited L2 vocabulary and resulting restricted reading comprehension (Kamil, Pearson, Moje, \& Afflerbach, 2011).

Table 3: Descriptive Statistics (Problem-Solving Strategy)

\begin{tabular}{|c|c|c|}
\hline NO & & Mean \\
\hline 7 & $\begin{array}{l}\text { I read slowly and carefully to make sure I understand what I } \\
\text { am reading. }\end{array}$ & 4.27 \\
\hline 9 & I try to get back on track when I lose concentration. & 4.06 \\
\hline 11 & I adjust my reading speed according to what I am reading. & 3.74 \\
\hline 14 & $\begin{array}{l}\text { When text becomes difficult, I pay closer attention to what I } \\
\text { am reading. }\end{array}$ & 4.02 \\
\hline 19 & $\begin{array}{l}\text { I try to picture or visualize information to help remember } \\
\text { what I read. }\end{array}$ & 3.69 \\
\hline 25 & $\begin{array}{l}\text { When text becomes difficult, I re-read it to increase my } \\
\text { understanding. }\end{array}$ & 4.26 \\
\hline \multirow[t]{2}{*}{28} & $\begin{array}{l}\text { When I read, I guess the meaning of unknown words or } \\
\text { phrases. }\end{array}$ & 3.71 \\
\hline & & 3.96 \\
\hline
\end{tabular}

Table 3 shows 9 items of Problem-solving strategy, only 7 items appeared positive answered by the participants. As shown above, the mean=3.96. It reflected that the participants usually apply these sub- strategies positively. Re-reading the text was one of their applied strategies to 


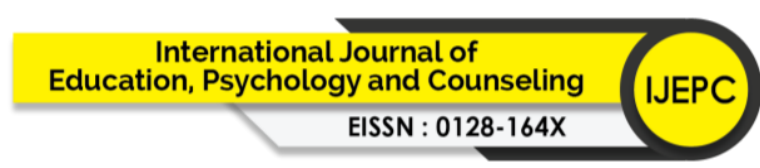

Volume 6 Issue 43 (November 2021) PP. 249-263

DOI 10.35631/IJEPC.643020

Special Issue: Issues and Challenges in English Education increase their understanding. Lastly, guessing of unknown words also favour their understanding.

Table 4: Effect Size For HPR And LPR

\begin{tabular}{cc|cccc}
\hline \multirow{2}{*}{ Strategy } & \multirow{2}{*}{ sd } & \multicolumn{2}{|c}{$\mathrm{H}$} & \multicolumn{2}{c}{$\mathrm{L}$} \\
\cline { 3 - 6 } GLOB & 0.53 & 3.87 & -0.74 & 2.17 & 2.46 \\
& & & & & \\
SUPP & 0.60 & 4.01 & -0.58 & 2.20 & 2.42 \\
& & & & & \\
PROB & 0.56 & 4.08 & -0.42 & 2.17 & 2.96 \\
\hline
\end{tabular}

\section{Magnitude of Effect for High (HPR) and Low (LPR) Proficient Readers Results}

In table 4 presented for GLOB results, the $s p$ (Standard of deviation) $=0.53$, with High Proficient Readers (HPR) Mean $=3.87$. The Low Proficient Readers (LPR) Mean $=2.17$. The es (Effect Size) for GLOB strategy for HPR is $\mathbf{- 0 . 7 4}$ and $\mathbf{2 . 4 6}$ for LPR. Second strategy is, SUPP. The $s p$ (Standard of deviation) $=0.60$. The Mean for HPR $=4.01$ and LPR Mean $=2.20$. In terms of the $e$, the $\mathbf{H P R}=\mathbf{- \mathbf { 0 . 5 8 }}$ and the $\mathbf{L P R}=\mathbf{2 . 4 2}$. Third strategy reported is the PROB; The sp (Standard of deviation) $=0.56$. The Mean for HPR $=4.08$ and LPR Mean $=2.17$. The es shows the $\mathrm{HPR}=\mathbf{- \mathbf { 0 . 4 2 }}$ and $\mathrm{LPR}=\mathbf{2 . 9 6}$.

The effect size shown by each strategy states here with the GLOB strategy es for HPR (-0.74) denotes there is a medium negative effect of this strategy used by the HPR. Whereas the LPR es = 2.46; signifies a very large effect which also implies that the LPR used this strategy for their text reading and understanding technique. Whilst the effect size for SUPP strategy; the HPR (-0.58) indicates that there is medium negative effect. Comparing to LPR (2.42), indicates that this strategy was used with very large effect to them. The final strategy PROB strategy exhibits the HPR es= -0.42 suggests that this strategy unlikely utilized in their reading and understanding with small negative effect to them. In contrast, the LPR claims that this strategy has a very huge effect with $e s=\mathbf{2 . 9 6}$.

Based on the findings above, it can be concluded that HPR stated that all three strategies give negative effect to them compared to LPR where all three strategies give large positive effect.

\section{Discussion}

The three strategies utilized by the participants namely, GLOB (Mean=3.70), SUPP (Mean= 3.70) and PROB (Mean= 3.96) reflected the participants claimed mostly 'always' or 'almost always' used the strategies with high mean. However, among three strategies, PROB strategy shows quite high than the two strategies. Thus, the focal point discussed would be on the PROB (Problem solving strategy) as the result shows interesting findings. 


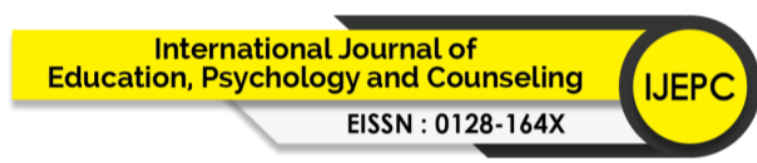

Volume 6 Issue 43 (November 2021) PP. 249-263

DOI 10.35631/IJEPC.643020

Special Issue: Issues and Challenges in English Education

PROB2 item statement: participants will read slowly and carefully to make sure that they understand what they read. In this case, the probability of readers of taking time to understand the text and the needs to read slowly and carefully due to interpretation of a printed message that influenced by the readers' personal background and history, knowledge and belief that brought in to constructing schemata to provide them the interpretive framework to comprehend the text discourse as suggested by Rummelhart (1977) and Ortony (1975). This connected to PROB3 item which states that they will try to get back on track when they lose concentration as they will find the connection between the information in the text with what they know. It also can be concluded that most of the participants categorised of using lower level reading processes and supported by Grabe \& Stoller (2002) whose identify poor L2 readers are slower in word recognition and generally weak at rapid and automatic syntactic processing because they developed an overt knowledge on L2 grammatical structures before they become fluent readers. As a result, they need to adjust their reading speed to understand the text better.

Coincidently with the claim made to answer the PROB4 item which states that they will adjust their reading speed according to what they are reading, when text becomes difficult, they will pay closer attention to what they are reading (PROB5), and the participants will try to picture and visualize information to help them to remember what they read (PROB7). PROB7 is also well supported in the Human Cognitive system (Newell \& Simon, 1972) where the readers will activate their working memory to transform the information into an internal form. Thus, when text becomes difficult, they will re-read to increase the understanding (PROB8).

On the other hand, to reflect the use of PROB8, Pressley \& Afflerbach (1995) have identified few aspects of the evident on verbal protocol on reading strategies. It is to highlight the part of aspects; (e) change strategies when understanding is not good and (f) monitor understanding and take action to correct inaccuracies in comprehension. This can be associated how the readers response when they claimed that they adjust the reading speed and re-read when the text become difficult. In fact, despite of the readers weakness, the PROB4 and PROB8 do contribute to the readers reading and understanding.

While PROB9 describes; when they read, they will guess unknown words or phrases. PROB9 can be concluded that the participants almost always use this sub-strategy. However, past longitudinal study by Parry (1991) proven that guessing word meaning from context is not a successful strategy in students' vocabulary development. According to Parry (1991), successful reader guesses less and read more so that they can expose themselves to many more words in meaningful context. In contrary, Phan (2006) stated that guessing meaning is also part of cognitive mental activities and considered as strategy.

\section{Conclusion and Implication for Practice}

Comprehension monitoring competency is particularly crucial to foreign language (L2) readers. Since L2 readers have a more limited knowledge of vocabulary and grammar and must decode meanings of texts by adopting strategies, they also need comprehension monitoring to further examine whether the strategies have successfully for L2 readers, as they will probably encounter more linguistic difficulties than L1 (native speaker) readers do and thus need to "repair more gaps in their understanding" through comprehension monitoring (Block, 1992, p. 320). Block argued that more studies should be done on L2 readers overcome their reading problems. Block indicated that most research related to comprehension monitoring has been 


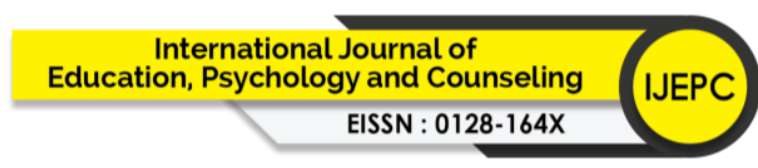

Volume 6 Issue 43 (November 2021) PP. 249-263

DOI 10.35631/IJEPC.643020

Special Issue: Issues and Challenges in English Education conducted with native English speakers. She claimed, though, that comprehension monitoring is more important for L2 readers, as they will probably encounter more linguistic difficulties than L1 (native speaker) readers do and thus need to "repair more gaps in their understanding" through comprehension monitoring.

The scarcity of this study does not permit the creation of any firm conclusions or generalizations about the effectiveness or success of utilizing reading strategies to specific students which the results may serve well in this context. This is on the basis that (1) how much of the questionnaire items can really describe the readers characteristics; (2) do all the items comprehensible sufficiently to the low proficient readers; and (3) do the items provided enough to cater the needs of high proficient readers. However, respectively, it can't be denied that the fact of positive essence that can be found in this study where the understanding of students' strength in certain reading strategy for instance the SUPP strategy can be highlighted for teachers to develop the skill with adjustments and needs for their students.

As a conclusion, this study will give attention to what extent does all of this imply in the field of EFL reading instruction. First, it is hoped that it may equip students with the competency of comprehension monitoring is equally significant with specific reading strategies. Comprehension monitoring is crucial because readers need to possess the ability to be aware of what kind of reading problems they are encountering, and what kind of strategies could be used to solve them. In addition, the ability of comprehension monitoring enables readers to integrate new information with either old or background knowledge as well as to detect whether the interpretation of texts follows both internal and external consistency (Baker, 1996).

\section{References}

Abdul Kadir B. Othman. (2005). Factors Contributing to Studentse Inability in Timely Completing Their Diploma Program: A Case of DOMT Students. Proceedings of Conference towards Academic and Service Excellence through Professionalism 2005, IRDC, UiTM Kampus Dungun, Terengganu.

Anderson, N. J. (1991). Individual differences in strategy use in second language reading and testing. The Modern Language Journal, 75, 460-472.

Auerbach, E. \& Paxton, D. 1997. "It's not the English thing": bringing reading research into the ESL classroom. TESOL Quarterly. 32/2:237-261.

Ausubel, D., (1968). Educational Psychology: A Cognitive View. New York: Holt, Rinehart and Winston.

Awang, Z. (2012). Research Methodology and Data Analysis. Malaysia: Penerbit Universiti Teknilogi MARA Press.

Baker, L. (1996) Social influence on metacognitive development in reading. In C. Cornoldi, \& J. Oakhill, (Eds.) Reading comprehension difficulties (pp. 331-351). Hillsdale, NJ: Lawrence Erlbaum Associates.

Barnett, M.A. (1989). More than Meets the Eye. Foreign Language Reading: Theory and Practice. Englewood Cliffs, N.J.: Prentice Hall Regents.

Block, E. L. (1992). See how they read: Comprehension monitoring of L1 and L2 readers. TESOL Quarterly, 26, 319-343.

Carrell, P. L. (1987). Content and formal schemata in ESL reading. TESOL Quarterly, 21, 461481. 


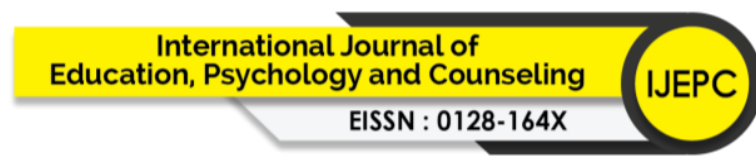

Volume 6 Issue 43 (November 2021) PP. 249-263

DOI 10.35631/IJEPC.643020

Special Issue: Issues and Challenges in English Education

Carrell, P.L. (1989). Metacognitive Awareness and Second Language Reading. Modern Language Journal. Vol.73, No.2, 121-134.

Carrell, P. L. (1992). Awareness of text structure: Effects on recall. Language Learning, 42, 120.

Carver, R.P. (1978). The case against statistical significance testing. Harvard Educational Review, 48(3), 378-399.

Chen, H. (1998). Constraints of English proficiency on understanding English ambiguous sentences in Chinese EFL learners. Modern Foreign Languages, 2, 1-16.

Cohen, J. (1988). Statistical power analysis for the behavioural sciences $\left(2^{\text {nd }}\right.$ ed). Hillsdale, NJ: Lawrence Erlbaum Associates.

Chua, Y.P. (2013). Mastering Resaerch Statistics. Malaysia: McGraw-Hill Education Sdn. Bhd.

Commander, N. E., \& Stanwyck, D. J. (1997). Illusion of knowing in adult readers: Effects of reading skill and passage length. Contemporary Educational Psychology, 22, 39-52.

Dell, G. S., McKoon, G., \& Ratcliff, R. (1983). The activation of antecedent information during the processing of anaphoric reference in reading. Journal of Verbal Learning and Verbal Behavior, 22, 121-132.

Flavell, J. H., Miller, P. H., \& Miller, S. A. (2002). Cognitive development (4th ed.). Upper Saddle River, NJ: Prentice Hall.

Flavell, J. (1979). Metacognition and cognitive monitoring: A new era of cognitive development inquiry. American Psychologist, 34, 906-911.

Flavell, J. (1976). Metacognitive aspects of problem solving. In L. B. Resnick (Ed.), The nature of intelligence (pp. 231-236). Hillsdale, NJ: Erlbaum.

Fletcher, J. M., Satz, P., \& Scholes, R. J. (1981). Developmental changes in the linguistic performance correlates of reading achievement. Brain and Language, 13, 78-90.

Grabe, W., \& Stoller, F. L. (2002). Teaching and researching reading. London: Longman.

Grabe, W. (1991). Current Developments in Second Language Teaching, TESOL Quarterly, 25, 375-406.

Garner, R. (1985). Metacognition and Reading Comprehension. Ablex Publishing, Norwood, NJ.

Gernsbacher, M. A. (1990). Language comprehension as structure building. Hillsdale, NJ: Erlbaum

Guthrie, J.T., Schafer, W.D. \& Huang, C. (2001). Benefits of opportunity to read and balanced reading instruction for reading achievement and engagement: A policy analysis of state NAEP in Maryland. Journal of Educational Research, 94(3), 145-162.

Haberlandt, K., \& Graesser, A. C. (1985). Component processes in text comprehension and some of their interations. Journal of Experimental Psychology: General, 114,357-374.

Hazenburg, S., \& Hulstijn, J. H. (1996). Defining a minimal receptive second language vocabulary for non-native university students: An empirical investigation. Applied Linguistics, 17, 145-163.

Just, M. A., \& Carpenter, P. A. (1987). The psychology of reading and language comprehension. Boston, Mass.: Allyn \& Bacon

Just, M. A., \& Carpenter, P. A. A (1980). Capacity theory of comprehension: Individual differences in working memory. Psychological Review, 99, 122-149.

Kamil, M. L., Pearson, P. D., Moje, E. B., \& Afflerbach, P. P. (Eds.). (2011). Handbook of reading research (Volume 4). New York and London: Routledge Taylor \& Francis Group. 


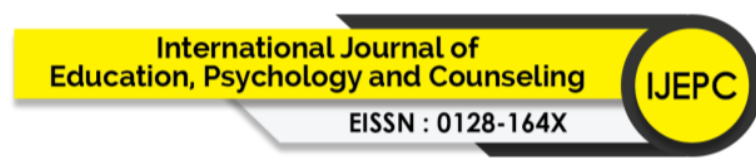

Volume 6 Issue 43 (November 2021) PP. 249-263

DOI 10.35631/IJEPC.643020

Special Issue: Issues and Challenges in English Education

Lane, G. G. (1999, November 17 - 19). Show me the magnitude! The consequences of overemphasis on null hypothesis significance testing. Paper presented at the annual meeting of the Mid-South Educational Research Association, Point Clear, AL.

Liu, Z., \& Bever, T. G. (2002). An experimental study of the function of syntactic analysis in reading comprehension]. Foreign Language Teaching and Research, 34, 219-224.

Manalu, T., \& Y. W.-T. C. on A., (2021) Metacognitive Strategies by Low Achieving Students in Reading Multimodal Texts. Atlantis-Press.Com. Retrieved from https://www.atlantis-press.com/article/125956103.pdf

Mokhtari, K. \& Sheorey, R., (2002), 'Measuring ESL students' awareness of reading strategies', Journal of Developmental Education 25(3), 2.

Nassaji, H. (2003). Higher-level and lower-level text processing skills in advanced ESL reading comprehension. The Modern Language Journal, 87, 261-276.

Newell, A. \& Simon, H.A. (1972). Human Problem Solving. Prentice Hall Inc. New Jersey: Englewood Cliffs

Nuttall, C. (2005). Teaching Reading Skills in a Foreign Language. Oxford: Macmillan.O'Malley, J. M., Chamot, A.U., et. al. (1994). Learning Strategies Used by Beginning and Intermediate ESL Students. Language Learning, (35): 21-46.

Ortony. A. (1975) "Why metaphors are necessary and not just nice". Educational Theory, Winter, 25, 45-53.

Palincsar, A. S., \& Brown, A. (1984). Reciprocal teaching of comprehension- fostering and comprehension-monitoring activities. Cognition and Instruction, 1, 117-175.

Parry, K. (1991). Building a vocabulary through academic reading. TESOL Quarterly, 25, $629-653$.

Phan, N. (2006). Effective Reading. Teachers Article, 11, 1- 4.

Piaget, J. (1955). The language and thought of the child. New York: World.

Pressley, M. (1998). Reading instruction that works: The case for balanced teaching. New York: Guilford.

Pressley, M., \& Afflerbach, P. (1995). Verbal Protocols of Reading: The Nature of Constructively Responsive Reading. Hillsdale, NJ: Erlbaum.

Rurmelhart, D.E. (1977). Introduction to Human Information Processing. New York: John Wiley and Sons.

Salataci, R \& Akyel, A. (2002). Possible Effects of Strategy Instruction on L1 and L2 Reading. Language Journal,14, 1.

Sheorey, R., \& Mokhtari, K. (2001). Differences in the metacognitive awareness of reading strategies among native and non-native speakers. System, 29(4), 431-449.

Smith, F. (1975). Comprehension and Learning. New York: Holt, Rinehart \& Winston.

Van den Broek, P. (1990). The causal inference maker: Towards a process model of inference generation in text comprehension. In D. A. Balota, G. B. d'Arcais, \& K. Rayner (Eds.), Comprehension processes in reading, 423 - 445. Hillsdale, NJ:Erlbaum.

Van Dijk, T. , \& Kintsch. W. (1983). Strategies of discourse comprehension. New York: Academic Press 